ХРОНИКА

DOI: $10.17805 /$ trudy.2017.2.10

\title{
НАУЧНАЯ СТУДЕНЧЕСКАЯ КОНФЕРЕНЦИЯ «АКТУАЛЬНЫЕ ПРОБЛЕМЫ СОВРЕМЕННОСТИ ОБЛАСТИ ОХРАНЫ ОКРУЖАЮЩЕЙ СРЕДЫ»
}

\author{
Т. А. Сошникова, В. С. Соина \\ Московский гуманитарный университет
}

Аннотация: В статье представлен обзор работы научной студенческой конференции «Актуальные проблемы современности в области охраны окружающей среды», которая прошла в Московском гуманитарном университете 11 апреля 2017 2.

Ключевые слова: Московский гуманитарный университет; студенческая наука; Год Экологии; студенческая конференция; обзор; проблемы экологии

\section{STUDENT SCIENTIFIC CONFERENCE “TOPICAL MODERN TIME ISSUES CONCERNING ENVIRONMENTAL PROTECTION"}

\author{
T. A. Soshnikova, V. S. Soina \\ Moscow University for the Humanities
}

Abstract: The paper presents an overview of the work of the Student Scientific Conference "Topical Modern Time Issues Concerning Environmental Protection", which was held at Moscow University for the Humanities on 11th April 2017.

Keywords: Moscow University for the Humanities; student science; Year of Ecology; student conference; overview; problems of ecology

11 апреля 2017 г. на юридическом факультете Московского гуманитарного университета состоялась научная студенческая конференция, посвященная Году Экологии. Эта конференция открыла Неделю студенческой науки в университете.

Целью проведения конференции являлось обсуждение ключевых направлений охраны природной среды, достижений в области экологии, предложений по решению экологических проблем, направлений деятельности органов власти и гражданского общества в Год Экологии, объявленный в 2017 г. в Российской Федерации. В конференции принимали участие студенты 1, 2 и 3 курсов юридического факультета, а также сотрудники Института географии РАН, кандидаты географических наук Н.С. Мергелов и А. В. Долгих. 
Вела конференцию декан юридического факультета МосГУ, доктор юридических наук, профессор Т. А. Сошникова и доцент кафедры гражданского процесса и социальных отраслей права МосГУ, кандидат биологических наук В. С. Соина. Обсуждение велось по двум направлениям: «Экологические проблемы глобального масштаба» и «Стратегия устойчивого развития в современном мире».

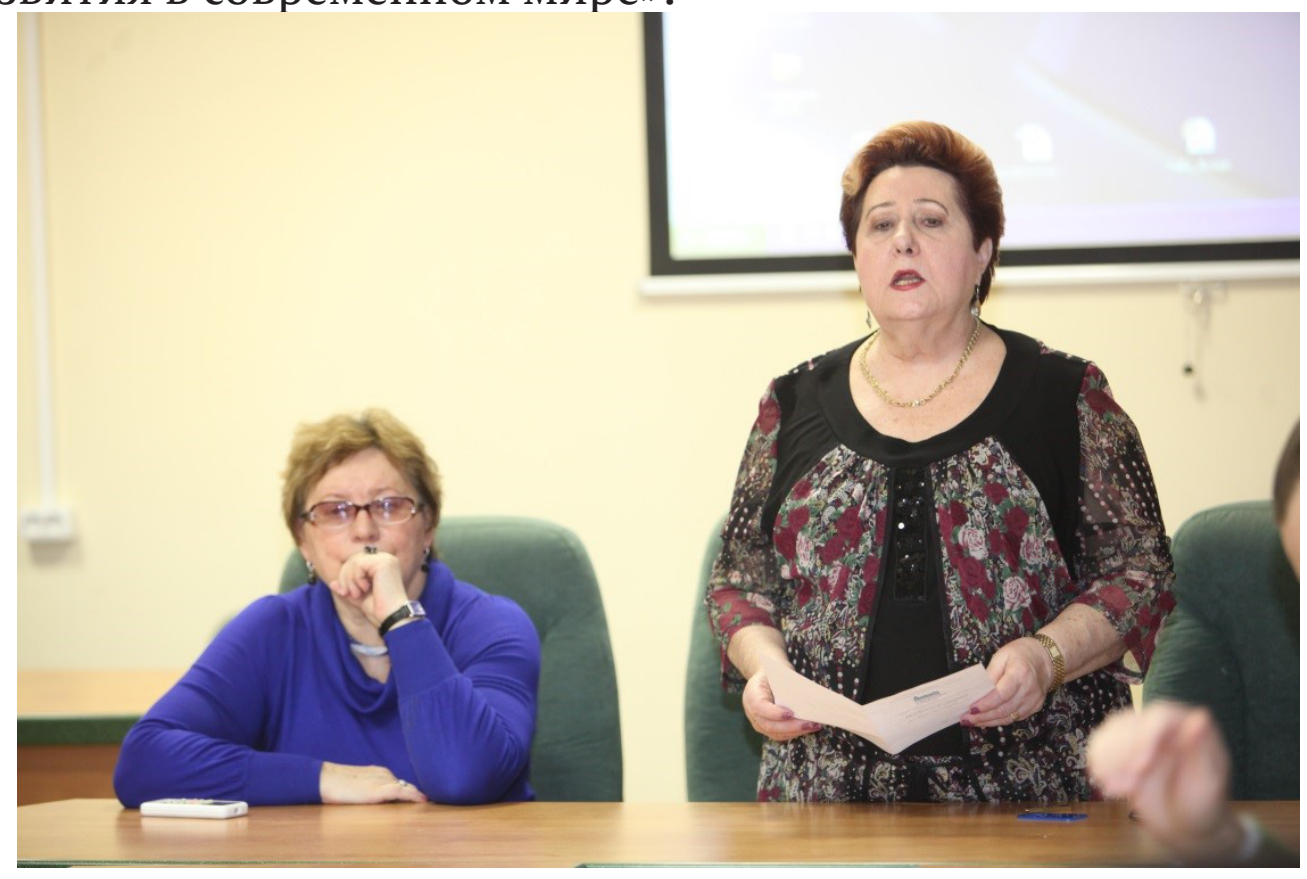

В докладе Н. С. Мергелова «Эксперимент человечества в Антарктиде: от юридических аспектов до расшифровки информации о древней природной обстановке на планете» обсуждался уникальный опыт международного сообщества по проведению научных исследований и сохранению природной среды Антарктиды, которая является самой большой заповедной территорией на Земле. Ее особый международно-правовой статус закреплен Договором об Антарктике (заключен в 1959 г. и вступил в силу в 1961 г). Подчеркивалось, что ледяной покров Антарктиды содержит наиболее полный архив информации о составе атмосферы планеты за последние $~ 800$ тыс. лет. Отмечалось, что многие участки континента, свободные ото льда территории, благодаря экстремальным условиям среды и изолированности, поддерживают экосистемы, которые возможно являются наиболее близкими современными аналогами тех экосистем, которые существовали на Земле до появления высших сосудистых растений и до антропогенного воздействия. Таким образом, Антарктида, как заповедная территория должна иметь наиболее высокий статус охраны со стороны международного сообщества.

В докладе А. В. Долгих на тему «Древние города Европейской России: история экстремального взаимодействия человека и природной среды» на примере древних городов Европейской России Москвы, Великого Нов- 


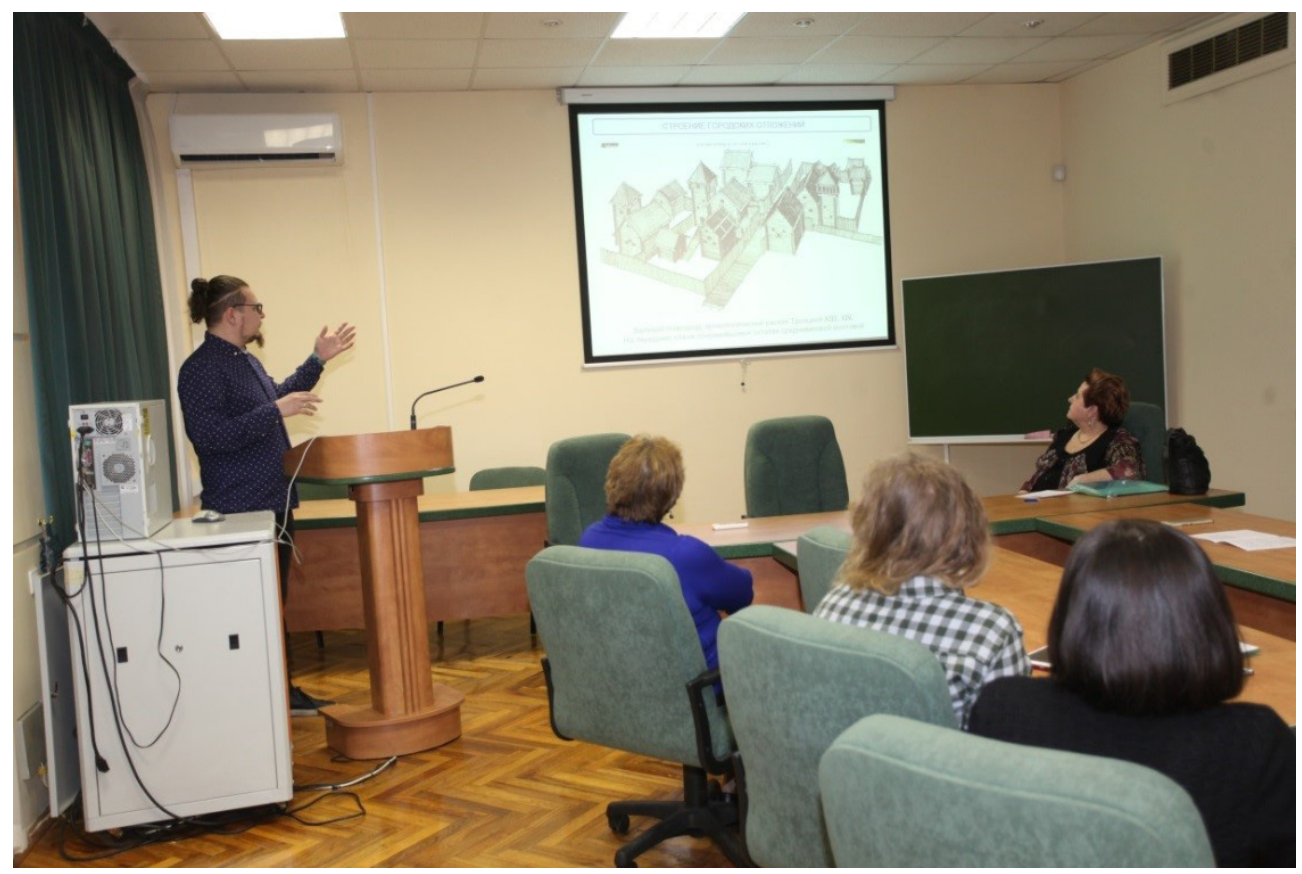

города, Старой Ладоги, Фанагории и др. было показано, как человек активно вовлекал в среду своего обитания новые элементы, изменяя ее химический состав. Важнейшим фактором формирования городской среды являлось поступление в почвы и отложения разнообразных химических элементов, что приводило к высокому накоплению тяжелых металлов (медь, цинк, свинец), мышьяка, иногда в очень высоких концентрациях. Было показано, что источниками загрязнения были такие виды деятельности человека как строительство, металлургическое производство, металлообработка, производство лаков и красок, гончарное ремесло, кожевенное производство и многие другие. Таким образом, автор делает вывод, что в древних городах население фактически уже сталкивалось со значительным загрязнением окружающей среды, однако, неспособность противостоять данному явлению привела к тому, что в культурных слоях древних городов было обнаружено более высокое содержание тяжелых металлов, чем в культурных слоях современных городов.

В докладах студентов Д. Живогляд, А. Д. Никишова и А. А. Воробьевой обсуждались проблемы глобального экологического кризиса. Отмечалось, что антропогенное воздействие человека на природу подошло к своей критической отметке. Экологическая обстановка на планете ухудшается, поэтому главной задачей является, по мнению авторов, определение приоритетов международной экологической политики. Авторы отмечают, что многие проблемы, такие, как выбросы парниковых газов, потепление климата, истощение озонового слоя, истощение запасов пресной воды, уничтожение лесов являются глобальными.

В докладе А. А. Воробьевой обсуждались два важнейших документа, затрагивающих охрану атмосферного воздуха - Киотский протокол и Парижское соглашение по климату. Отмечалось, что Парижское соглашение - соглашение в рамках Рамочной конвенции ООН об изменении клима- 
та, регулирует меры по снижению углекислого газа в атмосфере с 2020 г. Соглашение было подготовлено взамен Киотскому протоколу в ходе Конференции по климату в Париже и принято консенсусом 12 декабря 2015 г., а подписано 22 апреля 2016 г. Автор считает, что этот план должен иметь решающее значение на пути снижения темпов глобального потепления.

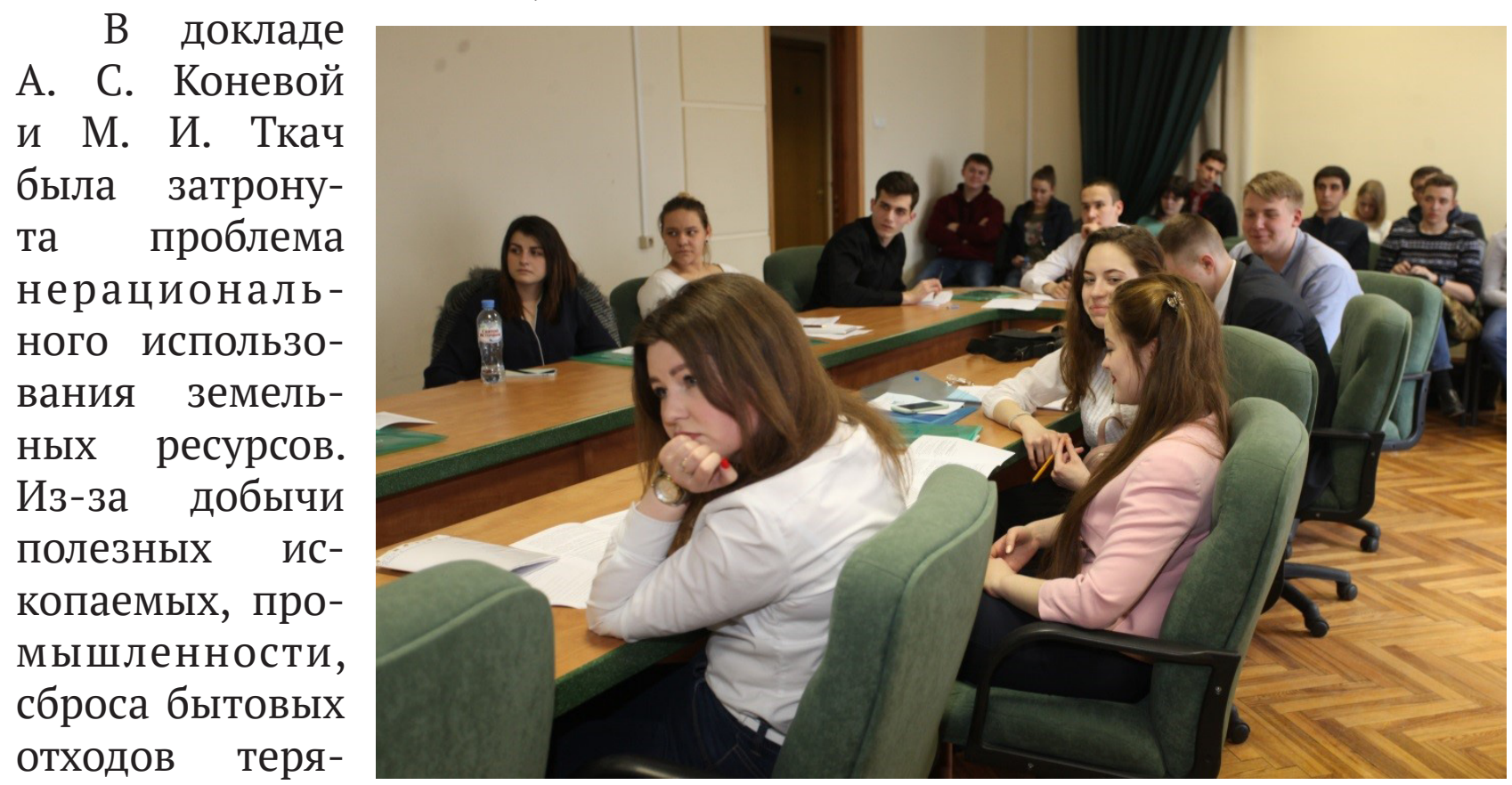

ется огромное

количество не просто земельного фонда, а плодородных почв, которые могли бы быть использованы во благо. Авторы остановились на главных мерах по сохранению земельных ресурсов и обратили внимание на то, что задачей правительств является обеспечение плодородия почв, а пашни продуктивностью.

А. И. Димитров в своем докладе обсудил одну из глобальных проблем современности - экологические проблемы лесов. По мнению автора, если лес уничтожить, то жизнь исчезнет с планеты. Это нужно осознать тем людям, от которых зависит сохранность леса. Интенсивная вырубка лесов - это не только уничтожение деревьев, но и животных, разрушение почвы. В целом леса покрывают приблизительно 30\% территории земли - это тропические леса, но также важное значение имеют северные хвойные леса. В данный момент сохранность леса является большой проблемой для многих стран.

А. В. Фащук и Г. В. Масленников отметили, что население нашей планеты год от года увеличивается, а вот численность диких животных наоборот сокращается. Человечество влияет на исчезновение большого количества видов животных, путем расширения своих городов, тем самым отнимая у фауны естественные места обитания. Очень важную роль играет то, что люди постоянно вырубают леса, осваивают все новые и новые 


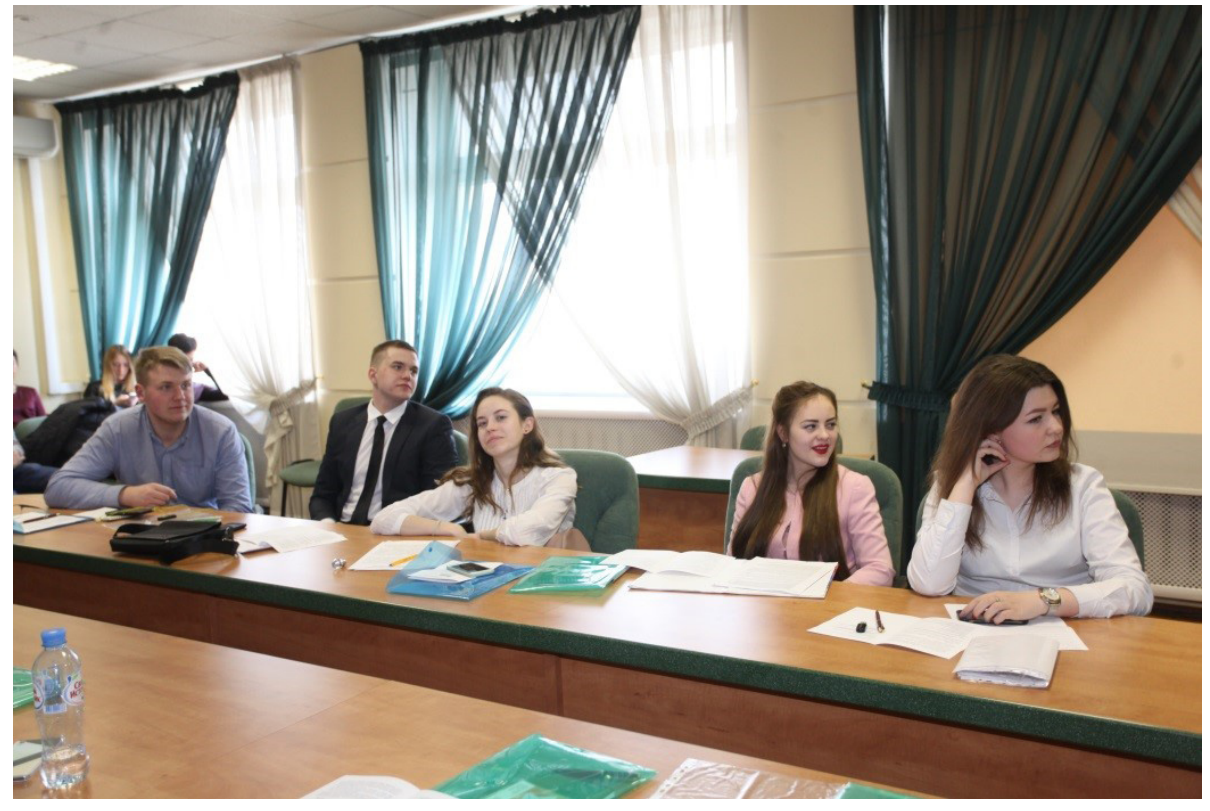

земли для посевов и загрязняют отходами атмосферу и водоемы.

На конференции также обсуждались экологические проблемы Арктики и Антарктиды. В докладах Д.А. Ильина и В.В.Марчук отмечалось, что, несмотря на то, что в Арктике, в основном, занимаются научно-исследовательской деятельностью, здесь есть некоторые экологические проблемы. Это - загрязнение окружающей среды и браконьерство, судоходство и добыча полезных ископаемых. Негативно на экосистему влияют и климатические изменения. Одной из крупнейших экопроблем Антарктиды считается таяние ледников. Это происходит из-за глобального потепления. Температура воздуха на материке постоянно повышается. Местами в летний период наблюдается значительное таяние льда. Это приводит к тому, что животным приходится приспосабливаться жить в новых погодно-климатических условиях, а в силу того, что, Антарктида является крупнейшим мировым заповедником, требуются усилия международного сообщества по сохранению уникального континента.

Еще одному уникальному природному объекту - озеру Байкал, был посвящен доклад Н. Н. Киселевой. Автор обращает внимание на несколько видов загрязнений - это загрязнение Байкала водами рек, воздушные выбросы над Байкалом, загрязнение Байкала хозяйственно-бытовыми стоками. Так, в Байкал сбрасываются отходы металлургических и строительных предприятий, переработки кожи и по добыче полезных ископаемых. В воду поступают нефтепродукты, агрохимикаты и различные удобрения сельского хозяйства. Автор подчеркивает, что Байкал - это уникальная природная экосистема, которая хранит огромные водные ресурсы. Антропогенная деятельность постепенно ведет к катастрофе, в результате которой водоем может перестать существовать, если не устранить негативные факторы загрязнения озера.

В докладе А. Н. Шувалова затрагивались экологические проблемы нефтяной промышленности, т. е. загрязнения биосферы нефтью. Автор обращает внимание на то, что основной причиной загрязнения окружаю- 
щей среды является то, что люди, используя нефть, допускают ошибки и не полностью контролируют производственный процесс, что и приводит к значительному загрязнению окружающей среды.

На конференции также обсуждалась оценка влияния факторов окружающей среды на здоровье человека и экологические проблемы Чернобыльской катастрофы. В докладах К. Паляничко и А. Е. Лаушкиной рассматривались климатические, химические и биологические факторы окружающей среды, влияющие на здоровье населения. Особое внимание было уделено результатам Чернобыльской трагедии. В докладе приводятся данные о высоком уровне заболеваемости населения. Авторы отмечают, что в результате Чернобыльской трагедии было загрязнено не менее 200000 кв. км Европы. Наиболее пострадали земли Украины, Белоруссии и России, но также радиоактивные выбросы осаждались частично на территории Австрии, Финляндии и Швеции. Это происшествие получило максимальную отметку (7 баллов) по шкале ядерных событий. Ущерб был нанесен биосфере полностью: загрязнен воздух, водоемы и почва. Авторы приходят к выводу, что подобные техногенные катастрофы требуют максимальных усилий для их предотвращения.

Обсуждение наиболее значимых глобальных экологических катастроф позволило сделать вывод о том, что к середине XX столетия возросшая мощь экономики превратилась из созидательной силы в разрушительную. Природные ресурсы не безграничны, поэтому международному сообществу потребовалось формирование новой модели развития цивилизации, способной противостоять глобальному экологическому кризису. Попыткой разрешить эту проблему стало создание новой концепции - Концепции устойчивого развития, которая обсуждалась в докладах Д. Р. Жданова, А. А. Леоновой и А. А. Артыкова. Собственно, концепция устойчивого развития общества была принята на Конференции ООН по окружающей среде и развитию, состоявшейся в июне 1992 г. в г. Рио-деЖанейро на уровне глав государств и правительств. По мнению авторов, сегодня эта концепция стала наиболее известной и даже модной глобальной моделью будущего мировой цивилизации.

Дата поступления: 20.04.2017 2.

Сошникова Тамара Аркадьевна - доктор юридических наук, профессор, заведующая кафедрой гражданского процесса и социальных отраслей права юридического факультета Московского гуманитарного университета. Адрес: 111395, Россия, г. Москва, ул. Юности, д. 5 . Тел.: +7 (499) 374-72-37. Эл. адрес: soshnikova.ta@mail.ru 
Соина Вера Сергеевна - кандидат биологических наук доцент кафедры гражданского процесса и социальных отраслей права юридического факультета Московского гуманитарного университета. Адрес: 111395 , Россия, г. Москва, ул. Юности, д. 5 . Тел.: +7 (499) 374-72-37. Эл. адрес: soina@ yandex.ru

Soshnikova Tamara Arkadievna, Doctor of Law, Professor, Head of Department of Civil Procedure and Social Branches of Law, Faculty of Law, Moscow University for the Humanities. Postal address: 5, Yunosti St., Moscow, Russian Federation 111395. Tel: +7 (499) 374-72-37. E-mail: soshnikova.ta@ mail.ru

Soina Vera Sergeevna,CandidateofBiology,AssociateProfessor,Department of Civil Procedure and Social Branches of Law, Faculty of Law, Moscow University for the Humanities. Postal address: 5, Yunosti St., Moscow, Russian Federation 111395. Tel: +7 (499) 374-72-37. E-mail: soina@yandex.ru

\section{Для цитирования:}

Сошникова Т. А., Соина В. С. Научная студенческая конференция «Актуальные проблемы современности в области охраны окружающей среды» [Электронный ресурс] // Научные труды Московского гуманитарного университета. 2017, № 1. URL: http://journals.mosgu.ru/trudy/article/view/456 (дата обращения: дд.мм.гг.). DOI: 10.17805/trudy.2017.2.10 